\title{
2-Cyanoethylmercapturic acid (CEMA) in the urine as a possible indicator of exposure to acrylonitrile
}

\author{
M JAKUBOWSKI, ${ }^{1}$ I LINHART ${ }^{2}$ G PIELAS, ${ }^{1}$ JKOPECK Yे \\ From the Institute of Occupational Medicine, ${ }^{1}$ Zódź, Poland, and Institute of Hygiene and Epidemiology, ${ }^{2}$ \\ Prague, Czechoslovakia
}

ABSTRACT The aim of this study was to evaluate the efficiency of metabolism of acrylonitrile (ACN) to N-acetyl-S-(2-cyanoethyl)-L-cysteine (2-cyanoethylmercapturic acid (CEMA) in man, the kinetics of excretion of this metabolite, and the relation between the uptake of $\mathrm{ACN}$ and the excretion of CEMA in urine. Eleven experiments were performed on six male volunteers exposed for eight hours to $\mathrm{ACN}$ at concentrations of 5 or $10 \mathrm{mg} / \mathrm{m}^{3}$. The average respiratory retention of $\mathrm{ACN}$ was $52 \%$ and $21.8 \%$ of the retained ACN was excreted as CEMA in urine. Elimination approximated first order kinetics with half life of about eight hours. The best correlation between the uptake 9 of ACN in the lungs and excretion of CEMA in urine was obtained when the concentration of CEMA in the urine fraction, collected between the sixth and eighth hours after the beginning of exposure, was adjusted to a specific gravity of $1.016(y=0.33 x-13 \cdot 3 ; r=0.83)$. CEMA excretion, however, cannot be used as an individual index of exposure.

According to the International Agency for Research on Cancer there is sufficient evidence for the carcinogenicity of Acrylonitrile (ACN) in animals. ${ }^{1}$ Though there is only limited evidence for the carcinogenicity of ACN in man it seemed worth while to investigate the absorption of $\mathrm{ACN}$ by all routes.

Acrylonitrile may be absorbed through the respiratory tract (the retention of vapour is $46 \%$ ) and liquid $\mathrm{ACN}$ is absorbed through the skin at the rate of $0.6 \mathrm{mg} / \mathrm{cm}^{2} / \mathrm{h}^{2}$ At present, no reliable method for evaluating internal exposure to $\mathrm{ACN}$ is available. ${ }^{3}$

So far attempts aimed at developing such a method have been based on the determinations of thiocyanates and free $\mathrm{ACN}$ in urine. ${ }^{45}$ High physiological values, evidently induced by smoking, ${ }^{3}$ interfere with the use of thiocyanates, whereas only $1-4 \%$ of the dose is excreted as free ACN as shown by the data of Sakurai et $a l^{4}$ and Houthuijs et al. ${ }^{5}$

Correlations between the concentrations of $\mathrm{ACN}$ in the air and excretion of $\mathrm{ACN}$ in urine are weak, according to Houthuijs et al $^{5}$; correlation coefficients ranged from 0.11 to 0.76 for postshift urine samples and from 0.14 to 0.69 for preshift urine samples. Data from animal experiments obtained by Kopecký $e t$ $a l^{6-9}$ Langwardt et $a l^{10}$, Ahmed and Patel, ${ }^{11}$ Van Blanderen et $a l^{12}$, and Sapota and Dramiński ${ }^{13}$ showed that CEMA is the main metabolite of ACH and that in rats about $50-60 \%$ of the dose is excreted in urine in this form. Therefore, excretion of CEM seems to have the potential to be an index of internal exposure to $\mathrm{ACN}$.

In preliminary studies Dramiński and Trojanowska confirmed the presence of CEMA in the urine of workers engaged in manufacturing acryl fibres (unpublished data). The concentration of CEMA in urine collected at the end of the shift varied between 25 and $350 \mathrm{mg} / \mathrm{l}$. The sensitivity of the method, however, did not allow for the evaluation of the kinetics of CEMA excretion in urine.

The present study aimed to determine the efficiency of ACN metabolism to CEMA, the kinetics of urinary CEMA excretion, and to find a correlation between CEMA excretion in the urine and the

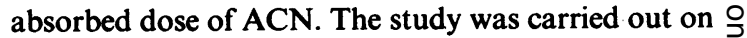
volunteers under experimental conditions.

\section{Materials and methods}

DETERMINATION OF CEMA IN URINE

To minimise possible errors, we decided to develop two independent methods for determining CEMA in $\sigma$ urine and to perform further determinations concurrently in both participating laboratories. Because of $\frac{\bar{D}}{\mathrm{D}}$ their close resemblance only one analytical procedure $\stackrel{\infty}{+}$ 
(Institute of Occupational Medicine in Kódź) has been described in detail together with basic information concerning both methods.

SYN THESIS OF CEMA

CEMA was synthetised after Vogel. ${ }^{14} \mathrm{~A}$ white crystalline product was obtained, $\mathrm{mp} 112-114^{\circ} \mathrm{C}$. Analytical calculations for CEMA: C, $44.44 \%$; H, $5.55 \%$; N, $12.96 \%$; S, $14.81 \%$; Found: C, $44.8 \%$; H, 5.86\%; $\mathrm{N}, 11 \cdot 47 \%$; S, $15 \cdot 28 \%$.

R E A G E N T S

(a) Standard solution of CEMA in ethyl alcohol: $2.5 \mathrm{~g} / 1(11.57 \mathrm{mmol} / \mathrm{l})$.

(b) Standard solution of $\mathrm{N}$-acetylomethionine (NAM) in ethyl alcohol: $2.5 \mathrm{~g} / 1(13.08 \mathrm{mmol} / \mathrm{l})$.

(c) Solution of diazomethane in diethyl ether $\left(\right.$ Vogel $\left.^{14}\right)$.

(d) Ethyl acetate, pa, Polish reagents, Gliwice.

(e) Sodium chloride, pa, Polish reagents, Gliwice.

\section{G A S CH ROM A T O GRA PH Y}

The determinations were carried out with a Varian type 2800 gas chromatograph equipped with an AFID detector. A glass column $(1 \mathrm{~m} \times 2 \mathrm{~mm}$ id $)$ packed with $3 \%$ OV-225 on Varaport 30 (100-120 mesh) was used. The oven temperature was programmed to increase from $140^{\circ}$ to $250^{\circ} \mathrm{C}$ at the rate of $10^{\circ} \mathrm{C}$ a minute; injector and detector temperatures were $180^{\circ}$ and $260^{\circ} \mathrm{C}$ respectively. Argon was used as a carrier gas at a flow rate of $40 \mathrm{ml} / \mathrm{min}$.

\section{PROCED URE}

To $2.5 \mathrm{ml}$ of urine, $0.1 \mathrm{ml}$ of NAM solution (internal standard) was added. The sample was then acidified with $50 \mu$ l of concentrated $\mathrm{HCl}$, saturated with $\mathrm{NaCl}$, and extracted with $25 \mathrm{ml}$ of freshly distilled ethyl acetate for 10 minutes. Then, after centrifugation, the organic layer was evaporated to dryness. The residue was dissolved in $0.25 \mathrm{ml}$ of ethanol and methylated with gaseous diazomethane. One microlitre of aliquot was used for each injection. Concentrations of CEMA were calculated from the ratio of the peak height of CEMA methyl ester and to that of an internal standard after previous calibration.

The second method differed from the first in using an isothermal column temperature of $218^{\circ} \mathrm{C}$ instead of the programmed temperature increase and in the use of CEMA 1-propyl ester as the internal standard.

Typical chromatograms of the urine extracts are presented in figs 1 and 2 . Within the range of concentrations up to $60 \mathrm{mg}$ CEMA/ 1 the relation between the concentrations of CEMA and CEMA/internal standard peak height (method 1) or peak area (method 2) ratios were linear. The detection limits of both methods were about $1 \mathrm{mg}$ CEMA/1 urine.
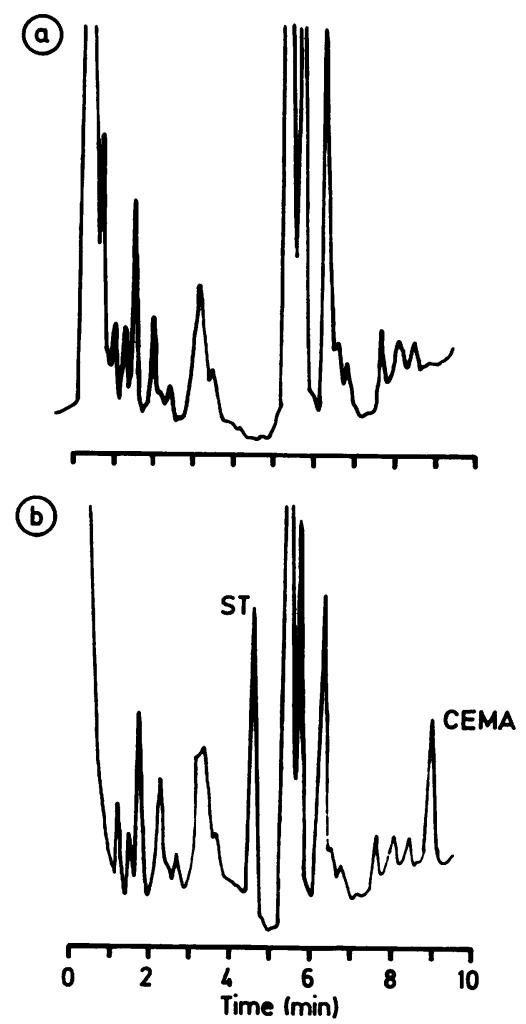

Fig 1 Typical chromatograms of urine extracts: (a) blank, (b) urine of an exposed person containing $15 \mathrm{mg} / \mathrm{l}$ of CEMA; ST-internal standard. (Method 1.)

Within-run relative standard deviations ranged from $\pm 11.0 \%$ to $\pm 8 \%$ (method 1$)$ and from $\pm 8.0 \%$ to $3.2 \%$ (method 2 ) for urinary CEMA concentrations of $10-60$ and $2-100 \mathrm{mg}$ CEMA/1 respectively. Between day imprecision, calculated from six determinations of CEMA solutions in urine during two weeks was within the range from \pm 5.0 to $\pm 9.0 \%$. Urinary solutions of CEMA kept at $+4^{\circ}$ and $-18^{\circ} \mathrm{C}$ were stable for at least two weeks.

\section{EXPERIMENTS INTO TOXICOLOGICAL C H A M B E R}

\section{Subjects}

The subjects of this study were six male volunteers aged 28-45 who showed no abnormalities in routine clinical examinations. All the volunteers (including the present authors) were toxicologists fully aware of the toxic properties of ACN.

\section{Exposure conditions}

The exposures were carried out in an exposure cham- 

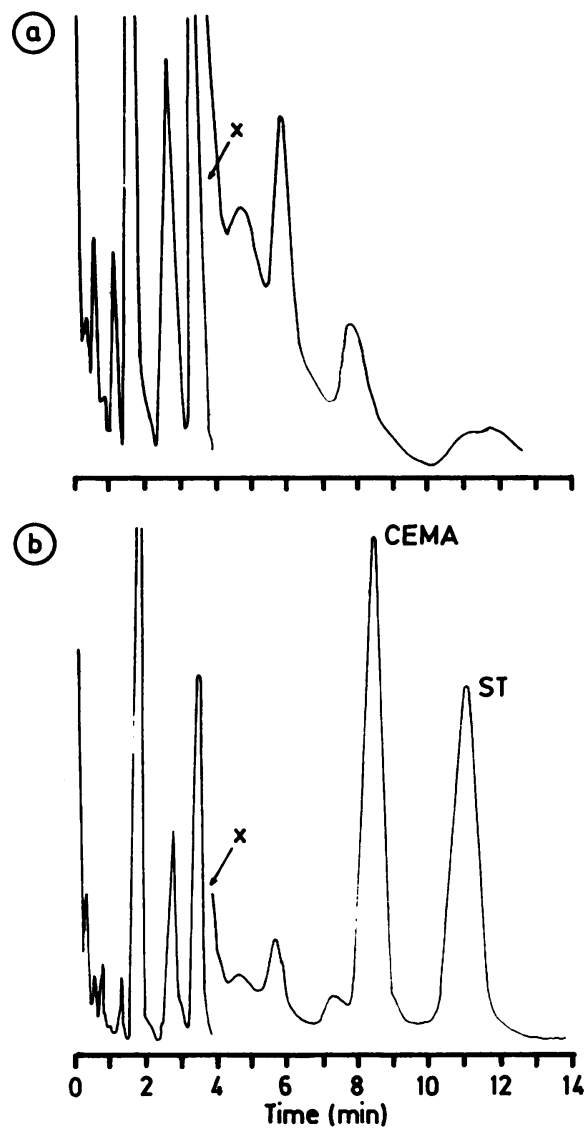

Fig 2 Typical chromatograms of blank (a) and spiked urine sample (b) containing $25 \mathrm{mg} C E M A / 1$; ST-internal standard. (Method 2.) $\times$ Attenuation reduced 10 fold.

ber at the Institute of Occupational Medicine (IOM) in Kódź. The chamber had a volume of $11.7 \mathrm{~m}^{3}$ and the ventilation was adjusted to about $200 \mathrm{~m}^{3} / \mathrm{h}$. ACN vapours were generated in a saturator immersed in the thermostated water bath and diluted with carrier air to produce the desired environmental concentration. ACN concentrations in the chamber were monitored by gas chromatography. The determinations were carried out with a GCHF-18.3 gas chromatograph equipped with an FID detector. A metal column $(3.5 \mathrm{~m} \times 4 \mathrm{~mm}$ id) packed with $10 \%$ Carbowax $20 \mathrm{M}$ on Chromosorb W/AW DMCS was used. The temperatures were as follows: oven $100^{\circ} \mathrm{C}$, injector $120^{\circ} \mathrm{C}$, detector $180^{\circ} \mathrm{C}$. Nitrogen was used as a carrier gas, at the flow rate of $30 \mathrm{ml} / \mathrm{min}$. Five millilitre air samples from the chamber were injected
Table 1 Exposure conditions

\begin{tabular}{|c|c|c|c|c|}
\hline \multirow{2}{*}{$\begin{array}{l}\text { Experiment } \\
\text { No }\end{array}$} & \multirow{2}{*}{$\begin{array}{l}\text { Noof } \\
\text { subjects } \\
\text { exposed }\end{array}$} & \multicolumn{3}{|c|}{ Mean concentration of $A C N$ in the chamber } \\
\hline & & $m g / m^{3}$ & $\mu \mathrm{mol} / \mathrm{m}^{3}$ & $s_{r}$ \\
\hline $\begin{array}{l}1 \\
2 \\
3 \\
4 \\
5 \\
6\end{array}$ & $\begin{array}{l}4 \\
1 \\
1 \\
1 \\
3 \\
1\end{array}$ & $\begin{array}{c}10.72 \\
10.7 \\
10.9 \\
5.59 \\
5.81 \\
5.42\end{array}$ & $\begin{array}{l}202 \\
202 \\
206 \\
105 \\
110 \\
102\end{array}$ & $\begin{array}{l}0.14 \\
0.09 \\
0.07 \\
0.13 \\
0.05 \\
0.11\end{array}$ \\
\hline
\end{tabular}

directly into the gas chromatograph every 15 minutes. with a gas tight Hamilton syringe.

The volunteers were exposed individually or in groups of three or four (table 1) to a constant concen- $\frac{\mathbb{D}}{3}$ tration of ACN approximating to the current Polish MAC value $10 \mathrm{mg} / \mathrm{m}^{3}\left(0 \cdot 187 \mathrm{mmol} / \mathrm{m}^{3}\right)$ or $5 \mathrm{mg} / \mathrm{m}^{3+}$ $\left(0.093 \mathrm{mmol} / \mathrm{m}^{3}\right)$ for eight hours with three 10 minute $\vec{N}$ breaks at two, four, and six hours after the beginning ${ }_{\omega}^{\infty}$ of the experiment. Table 1 gives data on the stability $y_{\circ}^{+}$ of ACN concentrations in the chamber.

Individual ventilation and retention of $\mathrm{ACN}$ in the lungs were measured in separate experiments. A volunteer sat outside the chamber, breathing air supplied ${ }_{\Phi}$ from the chamber through a mask. The outlet of the 3 mask was connected by plastic tubing (diameter $3 \mathrm{~cm}$, Ф length $50 \mathrm{~cm}$ ) to the three necked 21 flask. One outlet $\vec{c}$ of the flask was connected with the respirometer $\$ 000$ estimate expired air volumes. The samples of inhalsd. air were collected directly before the mask and thatef expired air from the centre of the flask and concenttrations of ACN were determined by means of gasō chromatography in conditions described above.

\section{Collection of urine samples}

Urine samples were collected after $2,4,6,8,10,12$, 응 $14,24,27$, and 31 hours from the start of exposure. The volume of each urine fraction and its creatinine concentration and specific gravity (in temperature about $22^{\circ} \mathrm{C}$ ) were measured. All samples were stored $\stackrel{\Phi}{3}$ in a refrigerator before the CEMA was determined.

Taking into account the relatively good correlation 3 . $(r=0.95 ; n=85)$ and concordance of the results of determinations performed in both laboratories $(\mathrm{IOM}=1.05$, Institute of Hygiene and Epidemiology, Prague $+1 \cdot 5$ ) the mean values of CEMA concentrations in urine are presented.

\section{Results}

Retention of ACN in the lungs averaged about $52 \% \mathrm{~N}$ (table 2) and about $22 \%$ of the retained ACN was metabolised to CEMA (table 3).

The kinetics of excretion of CEMA in urine was not uniform. The maximum rate of excretion occurred at different times after the beginning of exposure. Exam- $\stackrel{\infty}{+}$ 
Table 2 Retention of $A C N$ in the lungs

\begin{tabular}{|c|c|c|c|c|c|c|}
\hline \multirow{3}{*}{$\begin{array}{l}\text { Person } \\
\text { exposed }\end{array}$} & \multirow{3}{*}{$\begin{array}{l}A C N \text { conc } \\
\text { in chamber } \\
\left(\mathrm{mg} / \mathrm{m}^{3}\right)\end{array}$} & \multirow{3}{*}{$\begin{array}{l}\text { Lungs } \\
\text { ventilation } \\
(l / h)\end{array}$} & \multicolumn{4}{|c|}{ Retention of $A C N$} \\
\hline & & & \multirow{2}{*}{$\begin{array}{l}\text { Period of } \\
\text { observation }\end{array}$} & \multirow{2}{*}{$\begin{array}{l}\text { No of } \\
\text { determinations }\end{array}$} & \multicolumn{2}{|c|}{ Retention } \\
\hline & & & & & Mean & $s_{r}$ \\
\hline $\begin{array}{l}\text { RR } \\
\text { GP } \\
\text { AS } \\
\text { MP } \\
\text { MJ } \\
\text { IL }\end{array}$ & $\begin{array}{r}9.6 \\
8.2 \\
7.8 \\
9.6 \\
10.0\end{array}$ & $\begin{array}{l}508 \\
423 \\
366 \\
625 \\
620 \\
353\end{array}$ & $\begin{array}{l}90 \mathrm{~min} \\
90 \mathrm{~min} \\
90 \mathrm{~min} \\
90 \mathrm{~min} \\
8 \mathrm{~h} \\
\text { Not measur }\end{array}$ & $\begin{array}{l}8 \\
8 \\
8 \\
8 \\
8 \\
\text { an value }(51 \cdot 8 \%)\end{array}$ & $\begin{array}{l}58 \\
52 \\
51 \\
54 \\
44 \\
\text { s used f }\end{array}$ & $\begin{array}{l}0.09 \\
0.19 \\
0.08 \\
0.09 \\
0.07 \\
\text { ons }\end{array}$ \\
\hline
\end{tabular}

$S_{r}=$ Relative standard deviation.

Table 3 Relation between exposure to $A C N$ and excretion of urinary $C E M A$

\begin{tabular}{|c|c|c|c|c|}
\hline \multirow{2}{*}{$\begin{array}{l}\text { Experiment } \\
\text { No }\end{array}$} & \multirow{2}{*}{$\begin{array}{l}\text { Person } \\
\text { exposed }\end{array}$} & \multicolumn{2}{|c|}{$A C N$ uptake } & \multirow{2}{*}{$\begin{array}{l}\% \text { of dose excreted } \\
\text { in urine as } C E M A\end{array}$} \\
\hline & & $(m g)$ & $(\mu m o l)$ & \\
\hline $\begin{array}{l}5 \\
5 \\
5 \\
4 \\
6 \\
3 \\
1 \\
1 \\
1 \\
1 \\
2\end{array}$ & $\begin{array}{l}\text { AS } \\
\text { GP } \\
\text { RR } \\
\text { MJ } \\
\text { MP } \\
\text { IL } \\
\text { AS } \\
\text { GP } \\
\text { RR } \\
\text { MP } \\
\text { MJ }\end{array}$ & $\begin{array}{c}7.86 \\
9.26 \\
12.4 \\
11.0 \\
13.3 \\
13.9 \\
14.5 \\
17.1 \\
22.9 \\
26.2 \\
21.2\end{array}$ & $\begin{array}{l}148 \\
175 \\
234 \\
208 \\
251 \\
263 \\
273 \\
322 \\
431 \\
493 \\
398\end{array}$ & $\begin{array}{l}20.8 \\
20.1 \\
14.1 \\
12.8 \\
13.8 \\
28.9 \\
38.7 \\
27.5 \\
21.2 \\
22.5 \\
19.3\end{array}$ \\
\hline
\end{tabular}

$21 \cdot 8 \% ; s_{r}=0.35$.

ples of the kinetics of CEMA excretion in urine are presented in fig 3 .

To evaluate the kinetics of the excretion of CEMA, the mean values from all experiments were used. To eliminate the differences resulting from the absorbed dose depending on the concentration of $\mathrm{ACN}$ in the inspired air and individual retention and differences in the metabolism of ACN to CEMA, experimentally obtained excretion rates or concentrations of CEMA in urine were recalculated according to the equation:

Where:

$$
\mathrm{V}_{\mathrm{st}}=\mathrm{V}_{\mathrm{x}} \times \frac{\bar{S}}{\mathrm{~S}_{\mathrm{x}}} \times \frac{\overline{\mathrm{W}}}{\mathrm{W}_{\mathrm{x}}}
$$

$\mathrm{V}_{\mathrm{st}}=$ standardised rate of excretion (or concentration) of CEMA in urine

$V_{x}=$ rate of excretion or concentration obtained experimentally

$\overline{\mathrm{S}}=$ mean dose of ACN absorbed in all experiments

$\mathrm{S}_{\mathrm{x}}=$ dose absorbed during a given experiment

$\overrightarrow{\mathrm{W}}=$ mean excretion of CEMA in \% of absorbed ACN (table 3)

$\mathrm{W}_{\mathrm{x}}=$ excretion of CEMA in \% of absorbed ACN in the given experiment

The standardised values of the rate of excretion of CEMA or its concentration in the urine are presented in figs 4 and 5 . The descending parts of both curves are shown in fig 6 . They suggest first order elimination

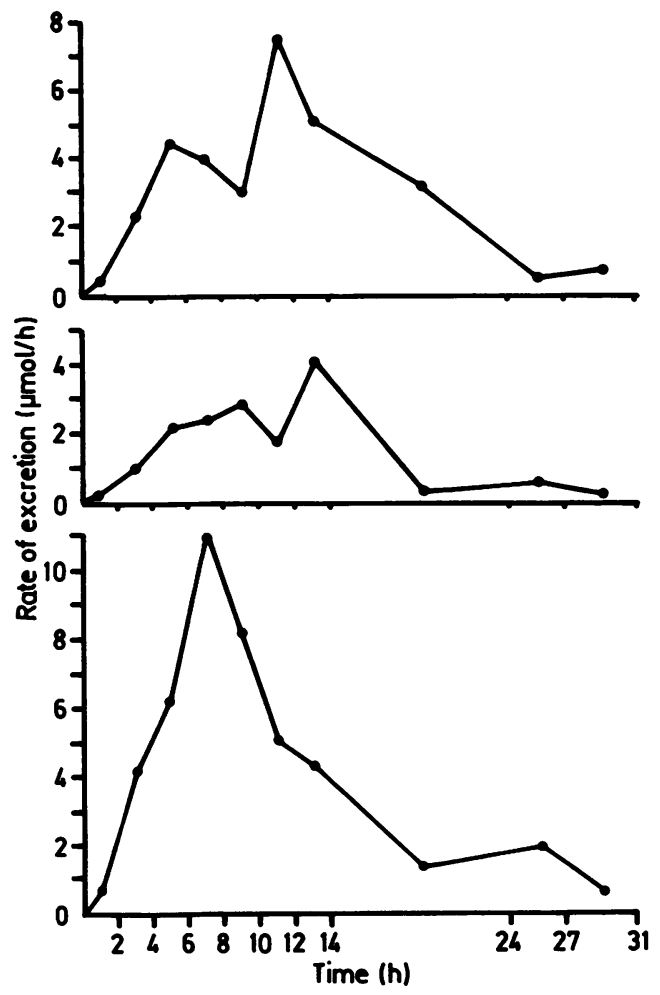

Fig 3 Examples of kinetics of CEMA excretion in urine.

of CEMA with half life values of about seven and nine hours.

Table 4 gives the relation between the uptake of ACN during experiments and the concentration of CEMA in the urine or its rate of excretion. The best correlation was obtained for the relation between the uptake and concentration of CEMA in fractions of urine collected between 6-8 and 4-8 hours after the beginning of exposure and adjusted to a specific gravity of 1.016 (fig 7). 


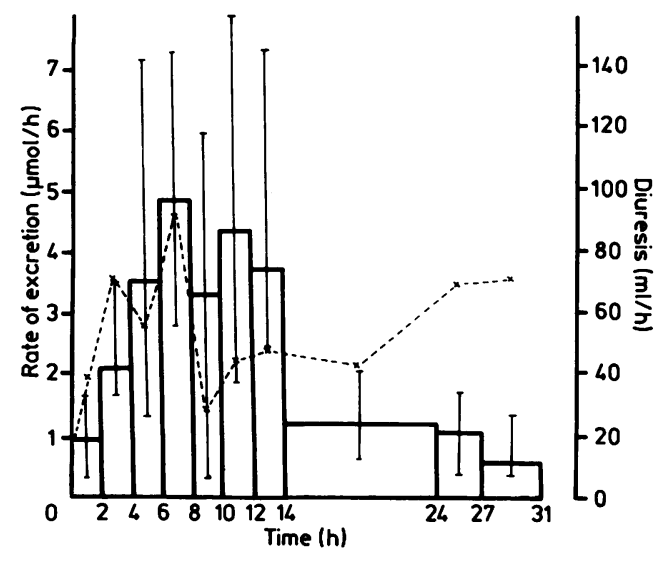

Fig 4 Mean values of standardised rate of excretion of CEMA in urine. Vertical bars indicate range of obtained values. $\times----\times$ diuresis.

Relative standard deviations of experimentally obtained points from the regression lines amounted to $\pm 29 \%$ for the urine fraction collected between six and eight hours after the beginning of exposure and $\pm 33 \%$ for the fraction collected between four and eight hours. Up to eight hours-that is, during exposure - there seemed to be some relation between the urinary excretion of CEMA and urine flow (fig 4). Correlation between the dose of $\mathrm{ACN}$ and the rate of excretion of CEMA was significant only when excretion was expressed for a 24 hour period (table 4). Correlations between the absorbed dose of $A C N$ and concentration of CEMA in urine corrected to the creatinine concentration were insignificant (table 4).

\section{Discussion}

A single eight hour experimental inhalational exposure to ACN at concentrations of $5-10 \mathrm{mg} / \mathrm{m}^{3}$ produced no subjective symptoms such as headache, nausea, or general weakness described at a similar level of industrial exposure. ${ }^{15}$

The retention of $\mathrm{ACN}$ in the lungs, averaging $52 \%$, was similar to the value of $46 \%$ reported by Rogaczewska and Piotrowski. ${ }^{2}$ It is interesting that the same subject exposed in 1968 had a retention of $49 \%$ and during the present experiment $44 \%$. It indicates that retention of acrylonitrile is constant through many years.

Because of the observed individual differences in the kinetics of CEMA excretion and relatively poor correlation between the uptake of ACN and concentration of CEMA in the urine (even when corrected to specific gravity $(\mathrm{sg})=1 \cdot 016)$, this test cannot be ap-

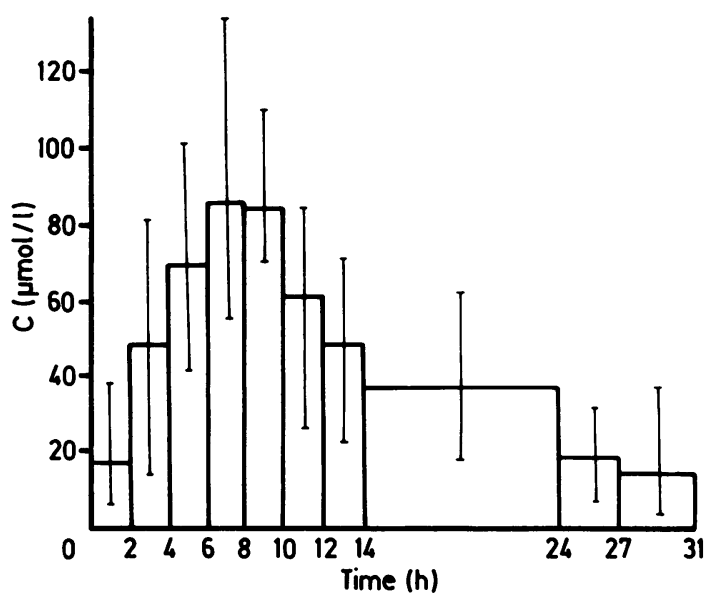

Fig 5 Mean values of standardised concentrations of CEMA in urine (sg corrected to 1.016). Vertical bars indicate range of obtained values.

plied as an individual index of exposure. It seems that it would be more reliable to accept the upper limit of $\mathbb{D}$

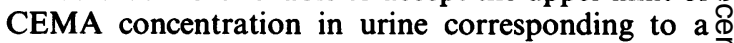
given concentration of $\mathrm{ACN}$ in air. Such an index would be useful in monitoring unexpectedly high $\stackrel{\oplus}{-}$ absorption-for example, through the skin.

The dose, which can be absorbed at the admissib concentration of $\mathrm{ACN}$ in the air, may be calculate according to the formula:

where:

$$
\mathrm{D}=\mathrm{C} \times \mathrm{R} \times \mathrm{V}
$$

C-ACN concentration in the air

$\mathrm{R}-\mathrm{ACN}$ retention in the lungs (about $50 \%$ )

$\mathrm{V}$-lungs ventilation (about $7 \mathrm{~m}^{3} / 8 \mathrm{~h}$ )

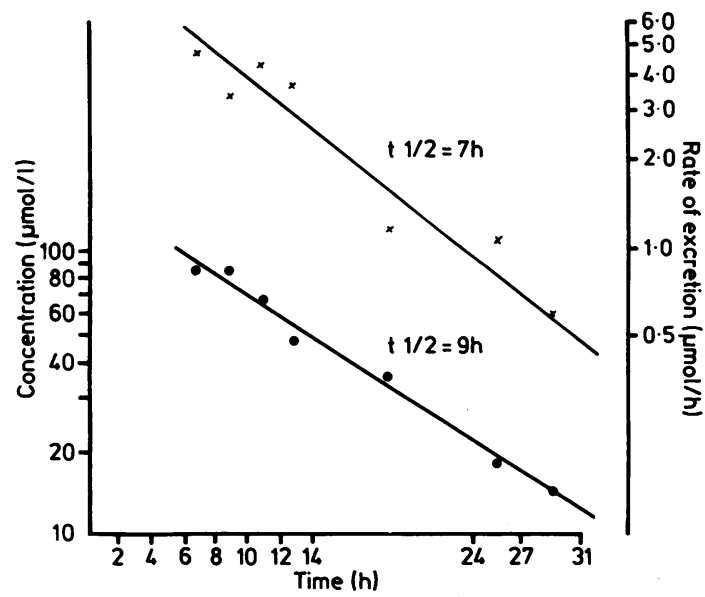

Fig 6 Descending parts of excretion curves of CEMA in urine. 
Table 4 Correlation between absorbed dose of ACM and excretion of CEMA in urine

\begin{tabular}{|c|c|c|c|c|c|}
\hline Urine fraction & $\begin{array}{l}\text { Relation between } \\
\text { ACN uptake }(\mu \mathrm{mol}) \text { and: }\end{array}$ & No & $\begin{array}{l}\text { Regression } \\
\text { equation }\end{array}$ & $r$ & $p$ \\
\hline \multirow[t]{3}{*}{$\begin{array}{l}4-8 \mathrm{~h} \text { from beginning } \\
\text { of exposure }\end{array}$} & $\begin{array}{l}\text { CEMA conc }(\mu \mathrm{mol} / \mathrm{l} ; \\
\text { sg corrected to } 1.016)\end{array}$ & 10 & CEMA $=0.285 \mathrm{ACN}-6.68$ & 0.78 & $<0.01$ \\
\hline & $\begin{array}{l}\text { CEMA conc }(\mu \mathrm{mol} / \mathrm{mmol} \\
\text { creat) }\end{array}$ & 10 & CEMA $=0.012 \mathrm{ACN}+1.35$ & 0.56 & NS \\
\hline & $\begin{array}{l}\text { Rate of CEMA excretion } \\
(\mu \mathrm{mol} / \mathrm{h})\end{array}$ & 11 & CEMA $=0.012 \mathrm{ACN}+0.56$ & 0.60 & NS \\
\hline \multirow[t]{3}{*}{$\begin{array}{l}\text { 6-8h from beginning of } \\
\text { exposure }\end{array}$} & $\begin{array}{l}\text { CEMA conc }(\mu \mathrm{mol} / \mathrm{l} ; \\
\quad \text { sg corrected to } 1.016)\end{array}$ & 10 & CEMA $=0.333$ ACN -13.3 & 0.83 & $<0.01$ \\
\hline & $\begin{array}{l}\text { CEMA conc }(\mu \mathrm{mol} / \mathrm{mmol} \\
\text { creat) }\end{array}$ & 11 & CEMA $=0.014 \mathrm{ACN}+1.84$ & 0.42 & NS \\
\hline & $\begin{array}{l}\text { Rate of CEMA excretion } \\
(\mu \mathrm{mol} / \mathrm{h})\end{array}$ & 11 & CEMA $=0.014 \mathrm{ACN}+0.98$ & 0.49 & NS \\
\hline $\begin{array}{l}0-24 \mathrm{~h} \text { from beginning } \\
\text { of exposure }\end{array}$ & $\begin{array}{l}\text { Rate of CEMA excretion } \\
(\mu \mathrm{mol} / 24 \mathrm{~h})\end{array}$ & 11 & CEMA $=0.197 \mathrm{ACN}+0.27$ & 0.73 & $<0.01$ \\
\hline
\end{tabular}

The dose corresponding to the United States TLV $\left(4.5 \mathrm{mg} / \mathrm{m}^{3}\right)$ and the proposed Polish MAC value $\left(2 \mathrm{mg} / \mathrm{m}^{3}\right)$ amounts to $15.7 \mathrm{mg}(290 \mu \mathrm{mol} / \mathrm{l})$ and $7 \mathrm{mg}$ $(130 \mu \mathrm{mol} / \mathrm{l})$ respectively. These two values are within the range covered by the test (fig 7).

On the basis of the regression curve (fig 7) and the relative standard deviation of the values obtained experimentally amounting to $\pm 29 \%$ one may calculate the mean values of CEMA concentrations in the urine which are equivalent to $\mathrm{ACN}$ concentrations in air and their fiducial ranges $^{16}$ in $90 \%$ of samples (mean $\pm 1.8 \mathrm{SD}$ ).

Such values would amount to:

(a) $84 \mu \mathrm{mol} / 1(40-128 \mu \mathrm{mol} / \mathrm{l})$ for the United States $\operatorname{TLV} 4.5 \mathrm{mg} / \mathrm{m}^{3}$

(b) $31 \mu \mathrm{mol} / 1(15-47 \mu \mathrm{mol} / \mathrm{l})$ for the proposed Polish MAC value $2 \mathrm{mg} / \mathrm{m}^{3}$.

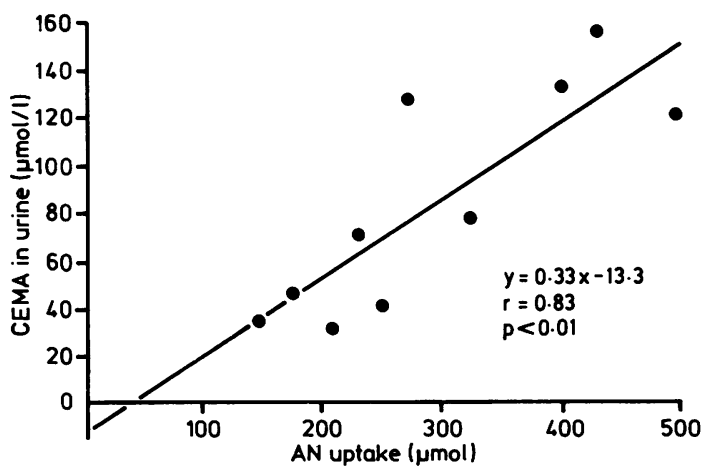

Fig 7 Relation between ACN uptake and concentration of CEMA in urine fractions collected between six and eight hours after beginning of exposure (sg of urine corrected to 1.016).
Any CEMA concentration in urine (sg corrected to 1.016) lower than $40 \mu \mathrm{mol} / 1$ would mean that $A C N$ absorption was below the United States TLV. Concentrations greater than $130 \mu \mathrm{mol} / 1$ strongly suggest that the uptake of $\mathrm{ACN}$ was higher than the permissible exposure.

As the half life of CEMA excretion in urine was about eight hours, one can predict the possibility of slight, approximately $10 \%$, increase of CEMA concentration in urine collected on the second day of exposure.

The described method should be evaluated under industrial conditions.

We thank our colleagues for participating in the experiments, Mrs I Hołub for synthesis of CEMA at the IOM, Lódź, Mrs L Heroldová and Mrs E Jabłońska for excellent technical help, and Mr A Olczyk for technical operation of the chamber.

This study was performed within the framework of UNDP supported project WHO/EURO/RER/82/002.

References

1 International Agency for Research on Cancer. Monographs on the evaluation of carcinogenic risk of chemical to humans Lyon: IARC, 1982: suppl 4.

2 Rogazewska T, Piotrowski J. Experimental evaluation of the absorption routes of acrylonitrile in humans. Med Pracy 1968;19:349-54.

3 Bertelli G, Berlin A, Roi R, Alessio L. Acrylonitrile. In: Alessio $\mathrm{L}$, Berlin A, Boni M, Roi R, eds. Biological indicators for the assessment of human exposure to industrial chemicals. Luxembourg: Commission of the European Communities, Industrial Health and Safety, 1984:5-13.

4 Sakurai H, Onodema M, Utsunomiya T, Minakuchi H, Iwani H, Matymumura $\mathrm{H}$. Health effects of acrylonitrile in acrylic fibre factories. Br J Ind Med 1978;35:219-25.

5 Houthuijs D, Remijn B, Willems H, Boleij J, Bierstecker K. 
Biological monitoring of acrylonitrile exposure. Am J Ind Med 1982;3:313-20.

6 Kopecký J, Gut I, Nerudová J, Zachradová D, Holeček V. Two routes of acrylonitrile metabolism. J Hyg Epidemiol Microbiol Immunol 1981;24:356-62.

7 Kopecký J, Gut I, Nerudová J, Zachradová W, Holeček V, Filip J. Acrylonitrile metabolism in the rat. Arch Toxicol 1980; suppl 4:322-4.

8 Kopecký J, Zachradovă D, Gut I, Filip J. Acrylonitrile metabolism in the rat in vivo. Pracovny Lekarstvi 1979;31:203-9.

9 Kopecký J, Gut I, Nerudova J, Zachradová D, Holeček V. Metabolic studies on acrylonitrile. In: Gut I, Cikrt M, Plas GL, eds. Industrial and environmental xenobiotics. Berlin: Springer Verlag, 1981:221-30.

10 Langwardt PW, Putzig CL, Braun WH, Young JB. Identification of the major urinary metabolites of acrylonitrile in the rat. $J$ Toxicol Environ Health 1980;6:173-282.
11 Ahmed AE, Patel K. Studies on the metabolism of aliphatic ni- $C$ triles. Toxicol Appl Pharmacol 1979;48:A91.

12 Van Blanderen PJ, Delbressine LPC, Hoogeterp JJ, et al. For- 으 mation of mercapturic acids from acrylonitrile, crotonitrile, and cinnamonitrile by direct conjugation and via an intermediate $\stackrel{\varnothing}{\varrho}$ oxidation process. Drug Metab Dispos 1981;91:246-9.

13 Sapota A, Dramiński W. The fate of ${ }^{14} \mathrm{C}$ acrylonitrile in rats. In: Gut I, Cikrt M, Plaa GL, eds. Industrial and environmental xenobiotics. Berlin: Springer-Verlag, 1981:231-7.

14 Vogel AJ. Textbook of Practical Chemistry. London: Longmans, 흐 1956.

15 Babanov GP, Kljucikov VN, Karajeva NJ, Liljeva ZV. Clinical $\underset{\mathbb{}}{\overparen{D}}$ symptoms of chronic poisoning by acrylonitrile. Vrach Delo 1959;8:833-6.

16 Imamura T, Ikeda M. Lower fiducial limit of urinary metabolite level as an index of excessive exposure to industrial chemicals. $\mathrm{Br}$. J Ind Med 1973;30:289-92. 